\title{
US-Japan science accord is signed at last
}

\section{Exchange of scientists and information - Patenting and classification fears denied}

\section{Tokyo}

CoOperative relations in science and technology between the United States and Japan entered a new era on Monday, when Prime Minister Noboru Takeshita and US President Ronald Reagan signed the new US-Japan Science and Technology Agreement at the economic summit meeting in Toronto. The 28-page agreement is a detailed framework for future cooperation. It outlines priority areas for research including biotechnology, superconductors and automation, measures to foster the exchange of scientists and information and rules to protect intellectual property rights.

To increase exchanges of scientists, the two governments will "provide substantial numbers of competitive fellowships in science and engineering for foreign nationals at their respective centres of excellence" and "continue to improve foreign language training programs" for them.

Japan has been criticized by some US officials because far moreJapanese scientists and engineers visit the United States than vice versa. Although funds to support several hundred fellowships for foreign scientists are now available, it remains to be seen whether the posts are filled - Japan has had difficulty attracting applicants for fellowship programmes with Europe and the United States.

Another problem is that about 80 percent of Japan's research and development is carried out in the private sector, which tends to be closed to outsiders. Japan's Ministry of International Trade and Industry (MITI), which supports many major research programmes in collaboration with industry, may in future encourage the private sector to include foreigners in them. But until US scientists begin banging on Japan's doors, the imbalance seems destined to remain.

The rules regarding intellectual property rights have been contentious, often delaying the negotiations. The agreement is meant to cover several eventualities. If an invention is made purely as a result of exchange of information (as at a seminar), the inventor may obtain all rights in all countries. In the case of exchange of scientists, the country that accepts the visiting scientist(s) may obtain all rights in all countries to inventions arising provided that the host country is "expected to make a major and substantial contribution to the program of cooperative activity".
But when that proviso does not apply, the host country can obtain rights in its own and third countries, while the visiting inventor can obtain patent rights only in his own country.

As an illustration, young scientists requiring training in the host country would forfeit patent rights to the host which applies to many Japanese scientists now visiting the United States. But, for joint research projects, intellectual property rights will be decided case-by-case, depending on how the costs are shared.

A high-level committee co-chaired by the Japanese Foreign Minister (or his designate) and the Science Adviser to the US President will review the operation of the agreement once a year, also assessing policies for the promotion of science and technology in each country and defining further initiatives.

In addition a working-level committee, chaired by the Japanese Foreign Ministry and the US State Department, with representatives from other agencies, will make recommendations to the high-level committee, issue an annual report and establish task forces to monitor the exchange of scientists and engineers and to improve access to information resulting from cooperation.

Finally, an advisory panel of eminent academic and industrial leaders from both countries will monitor the agreement and recommend areas for future research.

Concerns that the new agreement will clamp controls on research for reasons of national security seem unjustified. The agreement states that "no information or equipment classified for reasons of national defense will be utilized in cooperative activities" and both countries will support the "widest possible dissemination of information and equipment".

But the agreement does include a clause to prevent export of miltarily-useful information and equipment to "unauthorized destinations". And critics say the agreement should not be viewed in isolation. The United States and Japan recently agreed that classified US patents could be taken out in Japan (Nature, 332, $669 ; 1988)$. There are fears this agreement may lead to restrictions of jointly developed technology. But a Japanese foreign ministry official said that the secret patent agreement is totally unrelated to the new agreement, and cannot be used to classify technology developed in Japan.

David Swinbanks

\section{Canada's high hopes}

Toronto

THE Canadian government is about to begin the long process that it hopes will eventually lead to a global "Law of the Atmosphere". Assembling in Toronto next week for the World Conference on the Changing Atmosphere: Implications for Global Security will be 300 scientists, economists, legal experts and policymakers from more than 40 countries.

Canada's backing for the conference stems not so much from an enthusiasm for the scientific issues (Canada's scientific scene is surveyed in this week's issue of Nature, pages 717-736) but from its geographical position. Stuck between the world's largest industrial nations, it receives pollution from both: in the south, acid rain comes courtesy of the United States and in the north, arctic haze arrives from the Soviet Union and northern Europe (see page 736). These problems have brought an unusually high environmental consciousness to Canada's politicians. Last year's success in negotiating the Montreal protocol restricting the output of chlorofluorocarbons encouraged politicians to believe that international progress was possible. But that experience, plus the difficulties in negotiating away the problem of acid rain, has made it plain that nationalistic politics have to be avoided if the global "com. mons" is to be protected.

The conference is being billed as strictly non-political. Those attending will be briefed on the possible effect on climate of the greenhouse phenomenon, the depletion of the ozone layer and the long-range transport of pollutants. The conference will try to "set policy goals that will adapt to, control and if possible, prevent undesirable changes in the atmosphere".

Speakers want to avoid being seen as just environmentalists preaching conservation. In pre-conference briefings, serious attention was given to the possibility that a global warming might not be a bad thing for Canada after all. Henry Hengeveld, an adviser at the Canadian Climate Centre and member of the committee organizing the conference, believes a mid-latitude warming of $2-3^{\circ} \mathrm{C}$ would cause a polar warming of $10^{\circ} \mathrm{C}$. That would open up the north-west passage for shipping and make most of the east coast of Canada ice-free in winter.

The attempt by conference organizers to keep bilateral squabbling off the conference agenda has not, however, fully won over Canada's neighbour to the south. Fear that the conference may focus attention on US policy on acid rain means that no senior US administration official will attend.

Alun Anderson 